\title{
Familia, niñez y adopciones internacionales: reflexiones desde el trabajo social en el contexto peruano*
}

\author{
Jorge García Escobar *
}

\begin{abstract}
RESUMEN
Del lado de la representación colectiva la ocurrencia de hechos de abandono y de malos tratos en perjuicio de niños, niñas y adolescentes posiciona la idea de que la mejor solución sería dar en adopción a los infantes y adolescentes víctimas, a familias con mejores capacidades morales y materiales en comparación con sus familias de origen. Mientras que del lado de los profesionales del Trabajo Social, el debate se sitúa entre quienes consideran necesaria la medida de adopción y quienes consideran que deben agotarse todos los esfuerzos para que los niños, niñas y adolescentes no pierdan su familia de origen. El presente artículo constituye una primera entrada al debate abierto en torno a la actualidad y coherencia de la herramienta de la adopción internacional
\end{abstract}

Palabras clave: Adopciones internacionales / historia de la adopción internacional / derechos / paternidad biológica y social / trabajo social /género

\section{Family, childhood and international adoptions: reflections from social work in the peruvian context}

\section{ABSTRACT}

On the side of the collective representation, the occurrence of facts of abandonment and bad treatments to the detriment of children, children and adolescents positions the idea that the best solution would be to give the victim infants and adolescents in adoption to families with better moral and material capacities in comparison with their families of origin. Whereas on the side of the Social Work professionals, the debate lies between those who consider the adoption measure necessary and those that consider that all the efforts must be exausted so that the children and adolescents do not lose their family of origin. The present article constitutes the onset to open debate about the state of the art and coherence in the tool of international adoption.

Key words: international adoptions / history of international adoption / rights / biological and social parenthood / social work / gender

* Este articulo fue presentado originalmente con el titulo correspondiente a "Familia, niñez y mercado de las adopciones internacionales"

** Peruano. Licenciado y Magíster en Trabajo Social. Docente de la Escuela de Trabajo Social de la Universidad Nacional Mayor de San Marcos y de la Escuela de Trabajo Social de la Universidad Inca Garcilaso de la Vega.

Correo electrónico: jgarciae@unmsm.edu.pe 


\section{La concretización de los derechos de niño y niñas en la adopción}

Los esfuerzos del Trabajo Social por contribuir a la redefinición de las condiciones de vida y de bienestar de las personas, especialmente de los grupos sociales más desfavorecidos por la dinámica de desarrollo imperante, se concentran en una amplia variedad de espacios y procedimientos especializados, entre los cuales podemos destacar el proceso de adopción, tópico de renovada actualidad en el Trabajo Social internacional.

Pese a la inobjetable actualidad del tema de las adopciones internacionales en los colectivos académicos de Trabajadores Sociales de algunos países europeos y Estados Unidos, por el lado de los países de origen de los niños, niñas y adolescentes promovidos en adopción no se conoce de mayores análisis en profundidad de este fenómeno, ni mucho menos de investigaciones que den pistas sobre el devenir, efectos, avances, retrocesos y propuestas alternativas en el proceso de adopciones internacionales en su versión peruana.

El limitado desarrollo del campo de las adopciones en el Trabajo Social peruano es expresión por un lado del desconocimiento en relación a los limites y posibilidades de este espacio de intervención, preocupante más si se tiene en cuenta que el Perú por la complejidad de su problemática social y la creciente exclusión social es un país con altos índices de niñez abandonada y entregada en adopción. Por otro lado, también evidencia el poco peso otorgado en los ámbitos académicos y en la formación de pre grado a la adopción como un espacio para la intervención profesional, que integre una práctica orientada por procedimientos metodológicos avanzados y el interés permanente por generar conocimiento en relación a las múltiples realidades y configuraciones sociales que se encuentran en los procesos de adopción. Finalmente, también debemos mencionar que persiste aún una representación social que vincula principalmente a la adopción con el quehacer legal, para muchos pensar e involucrarse con este ámbito trae consigo la necesidad de asesoría legal.

Aportar desde el Trabajo Social a la defensa de los derechos humanos y a la gestión del desarrollo, expone a las y los profesionales a la necesaria profundización de la base teórica, metodología y procedimientos en los campos de intervención propios de la carrera, sobre 
todo si a lo que se apunta es a mejorar la calidad de vida de grupos sociales tan importantes como la niñez y adolescencia ${ }^{1}$, y mejorar la calidad de vida tiene directa relación con el reconocimiento y cumplimiento de los derechos humanos, expresados en diversos instrumentos legales internacionales y también en los marcos normativos nacionales.

En ese sentido, el pleno respaldo legal de la adopción como procedimiento válido y de la intervención psicosocial orientada a que a través de la adopción se asegure el bienestar integral de los niños, niñas y adolescentes, se encuentra expuesto en los instrumentos internacionales sobre derechos humanos de la niñez y adolescencia. Por ejemplo, la Convención Sobre los Derechos del Niño (CDN) en su artículo $20^{\circ}$ establece la posibilidad de la adopción como medida de protección y asistencia especial de los Estados para asegurar una familia para todo niño, niña y adolescente. Del mismo modo, en el artículo $21^{\circ}$ de la CDN se plantean con detalle las características de la adopción especialmente la internacional teniendo como base lo siguiente:

“...Los Estados partes que reconocen o permiten el sistema de adopción cuidarán de que el interés superior del niño sea la consideración primordial..."

El convenio internacional que profundiza el interés del sistema de Naciones Unidas por la promoción de la adopción de niños, niñas y adolescentes es "La Convención sobre la Protección de Menores y la Cooperación en Materia de Adopción Internacional", suscrita en La Haya - Holanda el 29 de mayo de 1993. Al respecto los principios rectores que sustentan este instrumento de derechos humanos son:

1 Hago esta diferenciación en relación a las poblaciones con las cuales intervienen las y los Trabajadores Sociales teniendo en cuenta el principio de interés superior de la niñez y adolescencia que sustenta que en toda decisión y acuerdo se debe buscar el beneficioso prioritario de los niños, niñas y adolescentes, y a la vez teniendo en consideración la diversidad de grupos humanos hacia los cuales este tipo de profesional dirigen sus intenciones y esfuerzos, que no necesariamente pueden ser parte de las poblaciones excluidas del desarrollo (me refiero a poblaciones de clase media alta y alta que en sus organizaciones también cuentan con Trabajadores Sociales), este planteamiento se encuentra desarrollado por el autor con mayor profundidad en su articulo "Ejes para un Trabajo Social acorde con los requerimientos del desarrollo". 
- Establecer garantías para que las adopciones internacionales tengan lugar en consideración al interés superior del niño y al respeto a los derechos fundamentales que le reconoce el Derecho Internacional (esto último se refiere a la obligatoriedad de los tratados internacionales y al respeto a las normas imperativas del derecho internacional).

- El reconocimiento de que para el desarrollo armónico de su personalidad, el niño debe crecer en un medio familiar, en un clima de felicidad, amor y comprensión.

- Que cada Estado deberá tomar, con carácter prioritario, medidas adecuadas que permitan mantener al niño en su familia de origen.

- El reconocimiento que la adopción internacional puede presentar la ventaja de dar una familia permanente a un niño que no puede encontrar una familia adecuada en su Estado de origen.

- "La Convención sobre la Protección de Menores y la Cooperación en Materia de Adopción Internacional" desagrega el conjunto de elementos legales a tener en cuenta para la plena comprensión y operacionalización de las adopciones internacionales. En términos generales del conjunto de elementos planteados podemos destacar los siguientes ${ }^{2}$ :

- La adopción debe de enmarcarse en una política global de la infancia y la familia, constituida por un abanico de medidas que deben de ser aplicadas de acuerdo a la especificidad presentada en cada caso (Preámbulo).

- Debe de asumirse la subsidiariedad de la adopción nacional en relación al mantenimiento o al regreso del niño a su familia de origen y prioridad de la prevención del abandono (Preámbulo).

- Para el desarrollo de un niño, niña o adolescentes es prioritario contar con una familia biológica o social antes que pensar en la institucionalización (Preámbulo).

- En la toma de decisiones sobre la adopción es prioritario dar una solución permanente que brinde estabilidad y seguridad al niño o niña (Preámbulo).

2 Para la elaboración del ordenamiento de los puntos medulares del Convenio de la Haya en materia de adopción me he basado en el listado previamente realizado por el Servicio Social Internacional - SIS y que se encuentra expuesto en el texto “Derechos del Niño en la Adopción Nacional e Internacional". 
- La adopción debe de ser entendida como una medida social y legal que busca la protección del niño o niña cuya situación la justifique como la mejor alternativa (Art. $1^{\circ}$ ).

- En el proceso adoptivo internacional deben de tenerse en cuenta los Estados de origen del niño, niña o adolescente y los Estados de acogida o de recepción, de donde provienen los adoptantes (Art. $2^{\circ}$ ).

- Debe anteponerse la protección del niño o niña frente al lucro, los abusos, el tráfico y la venta de niños y niñas (Preámbulo, Art. $1^{\circ}, 11^{\circ}$ y $32^{\circ}$.

- En la adopción debe de tenerse en cuenta el interés superior y derechos fundamentales del niño o niña, lo que implica atención a sus necesidades básicas (Art. $1^{\circ}, 4^{\circ}, 21^{\circ}, 29^{\circ}$ y $35^{\circ}$ ).

- En relación a adopciones internacionales debe enfocarse la subsidiaridad de la adopción internacional en relación a la adopción nacional (Art. $4^{\circ}$ ).

- La adoptabilidad psicosocial y legal de un niño debe de ser determinada luego de la realización de estudios especializados y el dictamen legal de abandono (Art. $4^{\circ}$ y $16^{\circ}$ ).

- Del mismo modo, la determinación de la capacidad e idoneidad de los padres adoptantes debe de ser establecida previos estudios especializados (Art. $2^{\circ}, 4^{\circ}, 5^{\circ}$ y $15^{\circ}$ ).

- En todo el proceso adoptivo debe darse una preparación especializada del niño o niña, la familia adoptiva y la familia biológica para que el proceso sea eficaz (Art. $4^{\circ}, 5^{\circ}$ y $9^{\circ}$ ).

- Cada Estado de origen de los niños y niñas que son promovidos en adopción debe generar una autoridad central en materia de adopciones (Art. $6^{\circ}$ ).

- Luego de la adopción durante la etapa denominada post adoptiva se debe contar con el apoyo de servicios cualificados para realizar el seguimiento (Art. $9^{\circ}$ ).

- A nivel de los Estados de donde provienen los adoptantes se generan agencias de adopción y su funcionamiento - intervención se da previo acuerdo entre los Estados (Art. 12º.

- Existe el derecho a la confiabilidad y reserva de la información sobre el niño o niña, la familia adoptiva y la familia biológica (Art. $16^{\circ}$ ). 
- Se platea del mismo modo el derecho del niño o niña a la búsqueda de sus orígenes biológicos y culturales (Art. $30^{\circ}$ ).

Lo expuesto en los instrumentos internacionales sobre la adopción ha sido retomado por el derecho peruano y más concretamente en la norma marco para el tema infancia y la adolescencia: el Código de los Niños y Adolescentes (Ley $N^{\circ} 27337$ ), promulgado en el año 2000, el mismo que expone el derecho de todo niño, niña y adolescente a tener una familia en su articulo $8^{\circ}$ :

"El niño y el adolescente tiene derecho a vivir, crecer y desarrollarse en el seno de su familia. (...) El niño y el adolescente que carece de familia natural tiene derecho a crecer en un ambiente familiar adecuado. El niño y el adolescente no podrán ser separados de su familia sino por circunstancias especiales definidas en la Ley y con la exclusiva finalidad de protegerlos. (...) Los padres deben velar porque sus hijos reciban los cuidados necesarios para su adecuado desarrollo integral..."

La definición de los componentes y tópicos que el Estado peruano destaca en el proceso de adopción esta desarrollado en el Código de los Niños y Adolescentes:

- Subsidiariedad de la adopción internacional en relación a la adopción nacional y priorización de las solicitudes nacionales (Art. $116^{\circ}$ ).

- Requisito de la declaración de abandono del niño, niña o adolescente para iniciar un proceso de adopción, exceptuando quienes tengan vínculo de parentesco o quienes hayan prohijado por espacio de dos años pero en la adopción judicial (Art. $117^{\circ}, 127^{\circ}$ y $128^{\circ}$ ).

- Autoridad Central del Estado peruano para las adopciones: Secretaria Nacional de Adopciones - SNA (dependiente del Ministerio de la Mujer y Desarrollo Social) responsable de la tramitación, programa, registro y supervisión del programa de adopción (Art. 118 $, 119^{\circ}, 120^{\circ}$ y $122^{\circ}$ ).

- Establecimiento de un Consejo de Adopciones multidisciplinario (con presencia de un representante del Ministerio de Justicia) que funcione para apoyar la adecuada toma de decisiones de la Secretaria Nacional de Adopciones (Art. 119²).

- Capacidad de la Secretaria Nacional de Adopciones para san- 
cionar a organizaciones y funcionarios que posibilitados de intervenir en el proceso de adopción ejerzan presión o brinden recompensas a fin de influenciar el proceso a favor de sus intereses (Art. $123^{\circ}$ y $126^{\circ}$.

- Posibilidad de adopciones internacionales sujetas a la existencia de un convenio previo entre los Estados (peruano y del país de origen de los solicitantes) y a la intermediación de un organismo acreditado de adopción, salvo si los ciudadanos extranjeros residieran más de dos años permanentemente en el Perú (Art. $129^{\circ}$ y $130^{\circ}$ ).

- Elaboración de informes periódicos en la etapa post adoptiva del proceso de adopción, responsabilidad de los padres adoptivos si es adopción nacional y de las organizaciones acreditadas de adopción si son adopciones internacionales (Art. $131^{\circ} \mathrm{y}$ $132^{\circ}$.

En síntesis el marco legal sobre adopción asumido por el Estado peruano se sustenta en el derecho fundamental de todo niño, niña y adolescentes de tener, gozar y vivir en una familia que le propenda los satisfactores materiales e inmateriales necesarios para su desarrollo integral. La adopción es un instrumento legal para lograr beneficios sociales para quienes constituyen el interés superior de nuestros estados:

“...La adopción es la formula jurídica que permite satisfacer el derecho de todo niño a tener una familia, cuando la familia biológica del niño, por múltiples razones, no puede atenderle. La figura de la adopción conjuga este derecho con el deseo de otras personas de ser padres..." (SEDA 1998: 1).

\section{Devenir histórico de las adopciones internacionales}

La ocurrencia de adopciones de niños y niñas es algo histórico, si bien es cierto la formalización o legalización de la adopción recién se desarrolla durante el siglo XX, se puede rescatar del trabajo de diversos autores importantes referencias en relación a la historia de las adopciones.

Por ejemplo según Buchanan la figura de la adopción internacional no es algo nuevo, para afirmar esto retoma un evento expuesto en el 
antiguo testamento, más específicamente en el Éxodo y en el verso en el cual se plantea la historia de Moisés un infante judío que es abandonado por su madre en una canasta en el río Nilo y es encontrado por la hija del Faraón de Egipto, quien lo adopta (Buchanan 2004: 1). La entrada al tema que sugiere Buchanan rompe con la comprensión mayoritaria de que las adopciones internacionales empezaron recién en el siglo XX.

Es más generalizada la perspectiva de que las adopciones nacionales si tienen su punto de partida antes del siglo XX, autores como Mustieles plantean que las adopciones de niños y niñas pueden ser históricamente rastreadas desde la antigua Roma (Mustieles 2000: 1). De otro lado, Florencia Altamirano sobre la base de los planteamientos de Leonidas Colapinto, retoma de éste el postulado de las dos etapas o momentos fundamentales en el devenir histórico de las adopciones nacionales; una primera etapa relacionada a concepciones antiguas como el "levirato" cuyo origen se encuentra en la antigua India y que de alguna forma es retomado por los pueblos Judío, Griego, Egipcio y Romano. En esencia esta forma primigenia de concebir la adopción tiene que ver con el aseguramiento de la descendencia familiar y la protección - transmisión del patrimonio familiar (Gamboa y Jiménez 1999: 207), la misma que en un inicio exponía a que las viudas jóvenes procrearan con el cuñado o pariente más allegado y que posteriormente posibilitó la adopción (Altamirano 2002: 40-41).

Altamirano también sostiene que habría sido el pueblo Romano el que por primera vez haría objeto de legislación a la adopción, estableciendo una doble modalidad, por un lado el "adoptio" referido al ingreso del adoptado en el grupo familiar en calidad de hijo ilegitimo o descendiente lejano, y por otro lado el "adrogatio" que supone la incorporación del adoptado y de todo su grupo familiar en un sistema familiar mucho más grande y pudiente (Altamirano 2002: 41).

El segundo momento clave referido por Altamirano comprende la etapa de perdida de vigencia de la adopción en la edad media y moderna y su reaparición inconstante en diversos marcos normativos, como por ejemplo el Código Francés impulsado por Napoleón en 1800 y la primera Ley de adopción norteamericana de 1851 . El instrumento de adopción norteamericano recién sería tomado realmente en cuenta con la finalización de la primera guerra mun- 
dial (Altamirano 2002: 41-42). En esta segunda etapa la figura de la adopción seguiría girando alrededor del interés de protección del patrimonio familiar y la permanencia de la descendencia, en ese sentido se trataba de una medida de apoyo familiar, más no de beneficio prioritario del niño o niña.

Linda Pollock en su trabajo "Los Niños Olvidados" que versa sobre las relaciones y procesos de crianza de los hijos e hijas entre los siglos XVI y XX a través del análisis de testamentos y diarios de padres y madres de familia, rescata el relato de una madre adoptiva norteamericana de nombre Mary Tucker quien vivió entre 1,775 y 1,806, y que hace referencia a su experiencia y sentimiento como madre de una hija adoptiva:

“...Este pequeño objeto crece día con día más cerca de mi corazón (...) Su comprensión está mucho más allá de sus años; su memoria es retentiva, su sensibilidad exquisita..." (Pollock 1993: 126).

“...Mi corazón me induce a quedarme en casa con mi pequeña pensionista (hija adoptiva) que tiene dos compañeras juguetonas con quienes divertirse. No las interrumpiré; son la compañía más acogedora y en ocasiones más instructiva..." (Pollock 1993: 242).

La cita rescatada por Pollock es una muestra del vínculo afectivo que podía llegar a desarrollar una adoptante con su adoptado o adoptada, esto es significativo si tenemos en cuenta que según la mayoría de autores, durante la edad media y moderna existía una escasa valoración de la niñez.

El fenómeno social de las adopciones internacionales vinculadas con un marco legal y político tiene su punto de partida y dinamización en la coyuntura europea posterior a la segunda guerra mundial (Mateo 1995: 39; Mustieles 2000: 1), específicamente en el periodo que va desde 1940 a 1950, lapso de tiempo en el cual se presentó un importante numero de niñas y niños huérfanos, quienes fueron luego adoptados por parejas de los países vencedores o que no participaron en la segunda guerra mundial (Mateo 1995: 39), específicamente familias de Estados Unidos, Canadá, Australia y Europa adoptaron niñas y niños huérfanos provenientes de Alemania, Italia y Grecia y en menor medida de China y Japón (UNICEF 2000: 2). La coyuntura de guerra entre naciones va a ser recurrente en el impulso de las adopciones internacionales durante el siglo XX, va a generar la 
condición de crisis y de necesaria ayuda humanitaria especialmente de los grupos sociales con mayores vulnerabilidades en contextos de desastre, como es el caso de los niños, niñas y adolescentes.

Las adopciones internacionales justificadas como respuesta humanitaria post guerra, se van a dinamizar con la ocurrencia la guerra de Corea, que posibilitó que entre los años 1950 y 1953 se adopten niños y niñas coreanas por parejas de países como Holanda y Suecia (Mateo 1995: 40). En muchos casos estos niños y niñas fueron hijos e hijas de madres coreanas y de padres militares estadounidenses quienes rápidamente se desentendieron de la responsabilidad de su reconocimiento y crianza, quedando en condición de niños y niñas sin padre, con paternidad ausente o simplemente abandonados. Tanto estos niños y niñas como sus madres fueron objeto de discriminación en sus países de origen, figura que se repetiría diez años después con los niños y niñas Vietnamitas, y que facilitaría su entrega para adopción (UNICEF 2000: 2).

Hacía finales de la década del 60 e inicios de la década del 70 se transforma la concepción de las adopciones internacionales, de ser vistas como una alternativa humanitaria frente a los estragos familiares y en la infancia causados por las guerras, pasan a ser enfocadas como "solidaridad con el tercer mundo" (UNICEF 2000: 2), perspectiva amplia que con el tiempo se iría precisando mejor hasta llegar a una visión de "solidaridad con la niñez y adolescencia de los países en vías de desarrollo". Esta redefinición de la racionalidad subyacente a las adopciones internacionales es el punto de partida para la presencia en el proceso adoptivo de la brecha entre adoptantes provenientes de países industrializados y adoptados nacidos en países del sur o en desarrollo.

La diferencia existente entre adoptantes pudientes, económicamente capaces de asegurar la calidad de vida material de cualquier niño, niña y adolescente y por otro lado niños, niñas y adolescentes con necesidades básicas insatisfechas, provenientes de núcleos familiares desestructurados y multiproblemáticos, es la condición en la cual se van a ir gestando un conjunto de nuevos elementos en el proceso de adopciones durante las tres últimas décadas del siglo $\mathrm{XX}$, como por ejemplo: la aparición de las agencias internacionales de adopción en los países desarrollados, entidades de derecho privado que ofrecen a costo y tiempo variable la posibilidad de lograr 
una adopción en la medida de lo posible rápida, de un niño o niña proveniente de diversas partes del mundo en desarrollo.

Gamboa y Jiménez alertan con relación a la emergencia de una renovada visión de la adopción internacional o una orientación moderna en la cual el centro del proceso adoptivo internacional es el derecho del niño, niña y adolescentes de contar siempre con una familia, y no necesariamente el de proveer de hijos o hijas a las parejas o personas que no pueden tener hijos biológicos (Gamboa y Jiménez 1999: 209). Esta renovada visión de la adopción más centrada en el bienestar integral de los niños, niñas y adolescentes tienen su sustento con la aprobación de la Convención sobre los Derechos del Niño y específicamente con el planteamiento del artículo $21^{\circ}$.

Aunque hoy esta visión centrada en el desarrollo del niño, niña o adolescentes se encuentra consignada en los instrumentos legales sobre adopción y en teoría se constituye en el referente normativo y político que impulsa las prácticas de los actores sociales que participan en los procesos adoptivos internacionales; adoptantes, adoptados, profesionales, agencias internacionales, el tema de las adopciones sigue siendo un tema controversial, finalmente esto tiene relación con el hecho de que los cambios normativos y políticos no necesariamente se condicen con inmediatos o mediatos cambios en las prácticas sociales, o dicho de otra forma la Ley puede decir una cosa pero la realidad mostrar otra.

\section{El aún difícil proceso}

Pese a los esfuerzos nacionales e internacionales por generar las condiciones para que el proceso de adopción internacional se perfeccione de modo que cumpla adecuadamente con sus objetivos en beneficio de la niñez y adolescencia, aún existen nodos problemáticos que dificultan arribar a los resultados esperados, aspectos que a nuestro entender son expresiones de problemas más profundos que demuestran que el respeto de los derechos de los niños, niñas y adolescentes aún es un proyecto inconcluso.

Una primera arista a observar con detenimiento es la referida al plano de las intromisiones mercantiles en el proceso de adopción, que se concretiza con el surgimiento de una fuerte demanda de niños, niñas y adolescentes de los países desarrollados afectados por un descenso en sus índices de natalidad y una oferta de los países en 
vías de desarrollo especialmente en los cuales el abandono, maltrato, explotación e institucionalización infantil es algo cotidiano, como es el caso del Perú.

Necesidades no satisfechas, la búsqueda de medidas que posibiliten su satisfacción y la legalización de la existencia e intermediación de servicios privados de apoyo a la adopción internacional, ha conllevado la generación de un mercado de las adopciones y como en todo mercado, éste que tendría que girar en torno al bienestar de la niñez y la adolescencia, cuenta con un versión formal e informal. Al interior del mercado formal como al interior del mercado informal se dan experiencias heterogéneas, es decir por un lado el plano del ámbito formal de las adopciones tiene un cariz mercantil concretizado por el funcionamiento de organizaciones que en los países desarrollados con el aval y licencia de sus Estados ofrecen sus servicios para facilitar la adopción de niños, niñas o adolescentes provenientes de países pobres, estas instancias pueden actuar realmente teniendo en cuenta el interés superior de la niñez o caso contrario atendiendo a sus intereses de acumulación económica y a los de sus prospectos de familias adoptantes.

Al tratarse de adopciones internacionales estos organismos acreditados de adopción además de contar con infraestructura y equipos profesionales en su Estado de origen, tienen que mantener representantes y/o filiales en los países en los cuales vía convenio pueden presentar e impulsar adopciones de niños o niñas, esto supone que el procedimiento puede ser seguido honestamente y con respeto al derecho de infancia en ambos países (el de origen de los adoptantes y el de origen del niño o niña en condiciones de ser adoptado). En caso contrario, en ambos países puede ser viciado el proceso por acciones reñidas con el derecho y la ética. Finalmente se puede dar también el caso en el cual, los organismos acreditados en sus países de origen tienen un accionar adecuado y socialmente valorado por su Estado y sus comunidades, y más bien la representación local de la misma organización en el país de origen de los niños y niñas a ser adoptados puede desarrollar prácticas ilegales con tal de concretizar una adopción (puede ser también de modo inverso).

Las posibilidades que dentro del ámbito formal los organismos acreditados de adopción procedan inadecuadamente, es un abanico de escenarios factibles a la luz de la intromisión de una racionalidad mercantil y empresarial en el procedimiento de adopción interna- 
cional. En el caso peruano se ha podido observar como los representantes locales de los organismos acreditados se esmeran y hasta compiten por información sobre niños y niñas disponibles para adopción, y por influir en las decisiones de la Secretaria Nacional de Adopciones y de sus profesionales sobre la promoción en adopción de niños y niñas ${ }^{3}$. A nivel internacional también es de destacar las situaciones en las cuales organismos acreditados de adopción se encuentran siendo procesados legalmente, como es el caso en España de las organizaciones: "Asociación de Defensa del Derecho de la Infancia a la Adopción - ADDIA" por daños morales e incumplimiento parcial de contrato o la "Asociación de Ayuda a la Infancia del Mundo - AAIM" por prácticas engañosas (Luale 2004: 4).

Como ya se había mencionado, paralelo a la formalidad y legalidad en los procesos de adopciones internacionales también se ha generado un mercado informal, delictivo, en el cual de forma oculta utilizando argucias legales, el pago de coimas, con engaños o a la fuerza se favorecen acuerdos mercantiles para propender adopciones, en las cuales los niños y niñas juegan el rol de simples mercancías de intercambio, con un costo o precio establecido. En el mercado delictivo de las adopciones ilegales se vinculan la trata de niños y niñas con el tráfico, y los fines que persiguen los adultos que están detrás de estas formas de vulneración de derechos humanos de los niños, niñas y adolescentes, pueden variar desde el objetivo de establecer una paternidad o maternidad con el niño que han podido escoger y pagar (a gusto del cliente), hasta la utilización en la diversas formas de explotación (sexual, en el tráfico de drogas), pasando inclusive por la venta de órganos de los niños y niñas víctimas. Una muestra de la forma delictiva e inhumana como acciona este mercado informal de la adopción, para el caso de la realidad paraguaya es el que detalla y documenta Rosa Ortiz en su libro "Adopción Internacional o Trafico de Niños", en el cual se muestran situaciones tan terribles como la existencia de "guarderías" en las cuales se mantenían a niños y niñas en condiciones infrahumanas para ser vendidos (Ortiz 1994: 19).

3 Este interés y prácticas tendientes a influir, incidir, facilitar decisiones a favor de adopciones para sus representados no necesariamente es tenida en cuenta por los profesionales de la Secretaria Nacional de Adopciones, la aceptación o no de estas formas de condicionamiento forma parte de las decisiones de las personas, profesionales que tienen la importante responsabilidad de actuar profesional y éticamente a favor de los derechos de los niños, niñas y adolescentes en condición de abandono. 
Una segunda arista vinculada con el plano de los modelos mentales y representaciones sociales, es el referido a los factores de inhibición para asumir la labor de la paternidad social. La adopción es una alternativa en primer lugar y preferentemente para posibilitar que un niño tenga una familia, y en segundo lugar para satisfacer la necesidad de una pareja o persona de tener, criar, proteger y amar a uno o varios hijos, alternativa que se fortalece ante la incapacidad biológica de procrear. Quienes no pueden procrear pueden asumir la medida legal y socialmente aceptada de la adopción, entonces tenemos dos posibilidades paternidad biológica y paternidad social que lamentablemente son interpretadas y valoradas de manera diferencial.

Un primer aporte importante para ampliar la comprensión de esta paradoja entre las posibilidades de ser madre y/o padre, es el esbozado por M. Alday, N. Ramljak y G. Nicolini quienes retomando a Eva Giberti plantean que para interpretar adecuadamente el proceso de adopción deben de tomarse separadamente reproducción - maternidad del sentimiento maternal (Alday, Ramljak y Nicolini 2001: 153), pues la posibilidad de procrear un niño o niña no necesariamente conlleva la formación automática del sentimiento y amor maternal, esto más bien responde a una construcción social a la luz de la interacción permanente entre padres e hijos o hijas.

La posibilidad de que dos o una persona opten por una paternidad social frente a la imposibilidad de tener hijos biológicos, en sociedades como la peruana aun fuertemente permeada por lo tradicional, no es fácil. Alrededor de la paternidad y maternidad se encuentran enfocadas un conjunto de mandatos y aspiraciones provenientes del entorno familiar y comunitario, las que al fin y el cabo apuntan al reconocimiento de la capacidad de procrear como fundamental para adquirir la personería social de padres y madres.

De entrada quienes adoptan tienen que enfrentar la dificultad de romper con los estereotipos de género en relación a la maternidad y la paternidad biológica, ya al no darse esta, se emiten mensajes de lástima, apoyo emocional frente a la incapacidad, sobre protección y subvaloración del hombre pero sobre todo de la mujer por no poder engendrar. Frente a esta situación, hacer pública la intención de adoptar trae muchas veces consigo la expresión por parte del entorno inmediato familiar de preocupaciones, prejuicios y consejos en relación a repensar la adecuación de una adopción y en caso de 
permanecer con la intención, el mensaje de entorno es mantener la mayor privacidad posible del proceso (Mateo 1995: 32).

La desigualdad de género expresada en el trato diferencial de los padres biológicos y los padres adoptivos o sociales, se puede verbalizar o simplemente puede formar parte de los implícitos en las relaciones familiares y comunitarias. Este es un tema complejo pero poco tocado públicamente por las instancias Estatales o privadas con participación en las adopciones. En tanto es tomado como parte del ámbito de lo privado, si la familia es un tema privado, mucho más lo serán las medidas como la adopción vinculadas con la incapacidad de procrear de un hombre o de una mujer. Visto así, el necesario cambio en las representaciones sociales de las personas en nuestras comunidades, representaciones de género que envuelven el acuerdo o desacuerdo por adoptar sigue y al parecer seguirá siendo un tema pendiente. Esto es contradictorio pues tanto el sentimiento paternal y maternal, son construcciones sociales antes que biológicas.

Una tercera arista o nodo critico del proceso de adopción internacional es el referido al vinculo con la familia de origen o padres biológicos de las niñas o niños promovidos en adopción, si bien es cierto los instrumentos internacionales y nacionales relativos a la adopción hacen mención de la subsidiaridad de las adopciones internacionales frente a las adopciones nacionales y a su vez la subsidiaridad de las adopciones nacionales frente a la posibilidad de que el niño o niña pueda mantenerse en su familia de origen, se puede observar que el trabajo preventivo con las familias que expresan interés por entregar a sus hijos e hijas en adopción es limitado, más aún si se trata de los padres biológicos cuyos hijos o hijas ya han sido adoptados.

Desde la etapa de decisión - aceptación de la entrega de un hijo o hija para adopción hasta el momento de crisis familiar posterior a la efectiva salida del niño o niña hacia otra familia (en este caso la adoptiva), se va diluyendo la importancia y atención de la familia de origen. No es de sorprender por lo tanto que pasados los años, cuando los que fueron niños o niñas promovidos en adopción internacional quieren saber un poco más sobre sus orígenes biológicos y culturales, no cuenten con ninguna referencia o información disponible. 
Sobre la familia biológica de los niños y niñas que son entregados en adopción en general recae un conjunto de representaciones y valoraciones negativas de irresponsabilidad y desnaturalización (especialmente sobre la madre biológica), razón por la cual muchas veces se opta por ir desapareciendo de la realidad de la niña o niño adoptado sus padres biológicos, es decir desde la comprensión y pensamiento unilateral de profesionales, funcionarios o padres adoptivos se decide que las familias biológicas son un problema social, que no deberían de conocer los niños o niñas que fueron procreados en esas familias y que fueron dados en adopción.

Si bien es cierto la determinación de los factores psicosociales por los cuales los padres deciden o se ven en la necesidad de entregar a sus hijos e hijas en adopción, es tarea de estudio y comprensión particular, pues cada caso es único e irrepetible (aunque pueden existir semejanzas y similitudes en algunos aspectos), es imprescindible revalorar la posibilidad de servicios y acciones que posibiliten el desarrollo de los sistemas familiares en los cuales se vienen madurando la decisión de entregar un hijo o hija en adopción. Tal como lo sugiere Maluccio, se debe de focalizar en la planificación de las acciones profesionales la posibilidad de la "permanencia", entendiendo que todo niño o niña tiene derecho a una familia, preferentemente su familia biológica (Maluccio 2000: 165). En correlación con este enfoque la intervención social pre adoptiva debería brindar las posibilidades para la mejora y desarrollo familiar antes que facilitar la extroversión de sus integrantes niños y niñas. Esto es coherente inclusive en los casos de las familias que ya han entregado a uno o varios de sus hijos e hijas en adopción, no dejarlas a su suerte no tratarlas como si fueran sistemas aberrantes, expulsores e invariables, sino por el contrario debería de continuarse el trabajo con estas familias a fin de contribuir permanentemente al mejoramiento de sus condiciones y dinámica de interacción y desarrollo.

Los servicios que por mandato del Estado se encargan en nuestros países de facilitar los procesos de adopción internacional, deberían prever y plantear medidas con las familias que han entregado a sus hijos en adopción, esto es un deber, una tarea sustentada en los derechos humanos, una responsabilidad. Ante la ausencia de estos servicios la recurrencia de familias permanentes proveedoras de niños, niñas y adolescentes abandonados y aptos para adopción será una constante. 
La cuarta arista o punto controversial en el proceso de adopciones internacionales en el Perú es el referido a la compleja relación entre celeridad y eficacia. El requerimiento de actuación con rapidez es una permanente en el discurso critico hacía el funcionamiento de la Secretaria Nacional de Adopciones, sobre todo cuando se toman decisiones en el devenir de un proceso de adopción que ponen en duda la coherencia, calidad y legalidad del mismo.

Si bien es cierto, los procedimientos burocráticos aún están presentes en los funcionamientos de las entidades del Estado en tanto medios legalmente regulados y prácticas culturales interiorizadas en las personas, esto no puede relacionarse o contrastarse con la importante y vital decisión que supone dar en adopción un niño o niña a una familia. Una decisión como una adopción debe de darse como parte de un proceso particular, dado que el matching o empatía entre el niño o niña adoptable y los potenciales adultos adoptantes no es algo que se de automáticamente, requiere de conocerse, aceptarse, valorarse plenamemente.

El planteamiento permanente de celeridad en los procesos de adopción pueden darse a costa de la limitada calidad en las etapas características de los procesos de adopción; pre adoptiva, adoptiva y post adoptiva. Es especialmente preocupante al respecto el caso de las adopciones internacionales pues las etapas del proceso muchas veces se pasan de manera acelerada, sobre todo con la segunda etapa; la etapa adoptiva en la que se da el encuentro entre adoptantes y niño o niña adoptada y se busca generar el matching o empatía. El tiempo o plazos de visita de las familias prospecto de adoptantes desde sus países de origen suelen ser muy cortos como para valorar integralmente si entre ellos y el niño o niña adoptable se genera el matching o empatía.

A la preocupación por el matching o empatía habría que sumarle que en buena medida estas adopciones internacionales son a su vez adopciones interculturales, pues las culturas, cosmovisiones y valores que poseen los integrantes de las familias adoptantes son diferentes a los que poseen los niños, niñas y adolescentes que son adoptados, definitivamente entre ellos tiene que darse de alguna forma y en momentos diferentes choques culturales, el proceso adoptivo también expone a una determinación cultural entre dos posibilidades; favorecer la permanencia, reconocimiento y respecto de los valores culturales del niños, niñas y adolescentes adoptados, 
o tender a eliminarlos tratando de imponer la nueva cultura de los padres adoptivos.

Las cuatro aristas o nodos críticos líneas arriba señalados son apenas un primer grupo de puntos sobre los cuales es necesario reflexionar aún más en relación a las adopciones internacionales, para entender claramente los limites y posibilidades de esta herramienta legal al servicio del bienestar y desarrollo de la infancia y adolescencia en condición de abandono, definitivamente con lo planteado no se agota la determinación de más pertinente en el devenir de los procesos adoptivos internacionales.

\section{Referencias bibliográficas}

ALDAY, M., RAMLJAK, N. Y NICOLINI, G. (2001). El Trabajo Social en el Servicio de Justicia. Aportes desde y para la intervención. Buenos Aires: Espacio.

AltamiRAnO, F. (2002). Niñez, Pobreza y Adopción ¿Una Entrega Social?; Un Estudio de Investigación desde el Trabajo Social. Buenos Aires: Espacio.

BIÑIÉS, P. (1998).

Familias de Acogida. Algo más que Solidaridad. En Revista Infancia y Adopción, (3).

BUCHANAN, T. (2004). The Impact of Attachment Theory on International Adoption: Implications of a Christian Worldview. Ponencia presentada en Friday Symposium of Dallas Baptist University. Dallas.

CÁCERES, D. (2001) Folleto Informativo para Defensorías del Niño y el Adolescente: La Adopción de Menores de Edad. Lima: PROMUDEH, AECI.

COLOMÉ, M. (1999). Se Buscan Familias. La Adopción de Niños y Niñas con Necesidades Especiales. En Revista Infancia y Adopción (6)

CONGIA, R. (2003). Un Viaggio nel Mondo Dell’Adozione. Una Proposta Pedagógica per la Formazione delle Famiglie. Tesi di Laurea in Pedagogia Sperimentale, Universita degli Studi di Bari. Bari.

FERREIRA, L. (2002). $\quad$ Aspectos Jurídicos da Intervencao Social e Psicológica no Processo de Adocao. En Revista Servico Social em Revista 5 (1).

GALLI, Y. (2004). Indicadores de Riesgo de Fracaso Adoptivo. Ponencia Presentada en el Seminario de Intercambio In- 
ternacional y de Reforzamiento Profesional: El Interés Superior del Niño y la Adopción. Lima.

GAMBOA, E. Y JIMÉNEZ, S. (1999). Análisis del Servicio Social de adopción infantil producido por órganos del Patronato Nacional de la Infancia: Consejo Nacional de Adopciones, Secretaria Técnica de Adopciones y las Oficinas de Puntarenas, Cartago y Limón durante 1997 - 1998. Tesis de grado no publicada. Universidad de Costa Rica. San José.

GIBERTI, E. (1992). La Adopción. Santiago, Chile: sudamericana

GROZA, V. (2003, Marzo). Adoption Near and Far for American Adoption Workers. Ponencia presentada en Adoption Opportunities Meeting. Washington DC.

International Adoption: An American Perspective. Documento Original. Ohio 2002.

Post Adoption Issues and Concerns. Ponencia presentada en Indian Council of Child Welfare. Nueva Delhi.

HOWE, D. Y FEAST, J. (2001). The Long - Term Outcome of Reunions Between Adult Adopted People and Their Birth Mothers. En British Journal of Social Work N³1.

LUALE, C. (2003).

Argentina. La Actuación de las Agencias en la Adopción Internacional. En AR: Revista de Derecho Informático, 62. http://www.alfa-redi.org/rdiarticulo.shtml? $\mathrm{x}=1284$

MALUCCIO, A. (2000). A A Competence - Centered Perspective on Child and Family Welfare. En: June y Morris, Robert (Eds.) Social Work at the Millennium, Hopps. New York: The Free Press.

MATEO, M. (1995). ¿Por Qué Adoptar en Otro País. Barcelona: CIES.

MUSTIELES, D. (2000). El Turno de Intervención Profesional en Adopciones Internacionales de la Comunidad Autónoma de Madrid. En Revista Trabajo Social Hoy, 27.

Consejo Nacional Sueco para los Asuntos de Adopciones Internacionales (1997). Adopciones Internacionales: Manual para las Comisiones de Asuntos Sociales. Estocolmo: AUTOR. 
ORTIZ, R. (1994). Adopción Internacional o Tráfico de Niños. Asunción: CIDE.

POLLOCK, L. (1993). Los Niños Olvidados: Relaciones Entre Padre e Hijos de 1500 a 1900. México DF: Fondo de Cultura Económica.

SOCIEDAD ESPAÑOLA PARA EL DESARROLLO DE LA ADOPCIÓN Y COMUNIDAD DE MADRID (1998). La Adopción: Guía Orientativa para Educadores. Madrid: AUTOR.

SERVICIO SOCIAL INTERNACIONAL (ed.) (2004). Derechos del Niño en la Adopción Nacional e Internacional. Cuaderno $N^{\circ} 1$. Ginebra: AUTOR.

FONDO DE LAS NACIONES UNIDAS PARA LA INFANCIA (1999). Adopción Internacional. En Innocenti Digest, 4. Recuperado el 10 de Septiembre de 2008. De http://white.oit. org.pe/ipec/documentos/unicef_tid_digest.pdf

VIERO, F. (2004). El Trabajo Tutelar y la Protección del Niño. Ponencia Presentada en el Seminario de Intercambio Internacional y de Reforzamiento Profesional: El Interés Superior del Niño y la Adopción. Lima. 